\title{
IncRNA/mRNA profiling of endometriosis rat uterine tissues during the implantation window
}

\author{
HAN CAI，XINXIN ZHU，ZHANFEI LI，YAPEI ZHU and JINGHE LANG \\ Department of Obstetrics and Gynecology, Peking Union Medical College Hospital, Beijing 100005, P.R. China
}

Received April 23, 2019; Accepted September 17, 2019

DOI: $10.3892 / \mathrm{ijmm} .2019 .4370$

\begin{abstract}
Endometriosis is associated with changes in long non-coding RNA (lncRNA) and mRNA expression, but the exact changes during the implantation window are unknown. Therefore, this study aimed to explore the lncRNA and mRNA expression profiles in the uterus of rats with endometriosis during the implantation window. A total of 35 non-pregnant female rats were randomized to the endometriosis $(n=13)$, adipose tissue control $(n=8)$ and blank control $(n=14)$ groups. On the 5th day of pregnancy, the rats were sacrificed to obtain uterine tissues. IncRNA and mRNA were analyzed using gene chips. A total of five differentially expressed lncRNA and four mRNA were validated by reverse transcription-quantitative (RT-q)PCR. Immunohistochemistry and western blotting were used to determine the expression of the ADAM metallopeptidase with thrombospondin type 1 motif 7 (Adamts7), tumor protein p53 (Tp53), distal-less homeobox 3 (Dlx3) and pyrimidinergic receptor P2Y6 (P2ry6) proteins. There were 115 upregulated lncRNAs, 51 downregulated lncRNAs, 97 upregulated mRNAs and 85 downregulated mRNAs in the endometriosis group. RT-qPCR confirmed the trends for five IncRNAs and four mRNAs (Adamts7, Tp53, Dlx3 and P2ry6). The relative protein expression levels of Adamts7, P2ry6, D1x3 and TP53 were significantly different in the endometriosis group ( $\mathrm{P}<0.05$ vs. controls). Bioinformatics predicted the co-expression relationship of the selected five lncRNA and four mRNA. Gene ontology and the Kyoto Encyclopedia of Genes and Genomes predicted that Adamts7, P2ry6, Dlx3 and TP53 were involved in endometriosis-related inflammation and reproductive pathways. In conclusion, the changes in
\end{abstract}

Correspondence to: Dr Jinghe Lang, Department of Obstetrics and Gynecology, Peking Union Medical College Hospital, 1 Shuaifuyuan, Dongcheng, Beijing 100005, P.R. China

E-mail: langjinghe1555@sina.com

Abbreviations: cDNA, complementary DNA; H\&E, hematoxylin and eosin; lncRNA, long non-coding RNA; PCC, Pearson's correlation coefficient

Key words: endometriosis, infertility, long non-coding RNA, mRNA the expression of lncRNAs, mRNAs and proteins (Adamts7, P2ry6, D1x3 and TP53) may possibly affect endometrial receptivity in rats with endometriosis during the implantation window, probably resulting in implantation failure of the embryo.

\section{Introduction}

A total of $\sim 2-10 \%$ of women suffer from endometriosis and $50 \%$ of them have infertility issues (1), mainly of the estrogen-dependent inflammatory type $(2,3)$. The glandular epithelium and basement membrane of human endometrium undergo periodic changes in gene expression, which must be synchronized to allow the opening of the implantation window. Any abnormality in gene expression could lead to a small or absent window. The abnormal inflammatory state caused by endometriosis impairs endometrial receptivity (4).

Long non-coding RNAs (lncRNAs) are non-coding RNAs with a length of $>200$ nucleotides and a wide range of biological functions. A number of studies reported various lncRNAs to be associated with endometriosis and compromised fertility (5-8) A total of two genome-wide screening studies showed that there were 1,000 lncRNA (9) and 1,300 mRNA (10) transcripts that were abnormally expressed between eutopic and ectopic endometrial tissues of patients with endometriosis. Another study revealed that 1,277 lncRNAs and 1,216 mRNAs were differentially expressed between the eutopic and ectopic endometrium of patients with endometriosis during the late secretory phase (11). Taken together, these studies highlight the important regulatory roles of lncRNAs in endometriosis.

In the present study, the difficulty of obtaining clinical specimens of the endometrium during the implantation window was taken into consideration. Therefore, autologous endometrial transplantation was used to establish a model of endometriosis in Sprague-Dawley rats. The present study aimed to determine the changes in lncRNAs and mRNAs in the uterine tissues of those rats during the implantation window, using microarrays. The present study hypothesized that the abnormalities in lncRNA and mRNA profiles have significant effects on the implantation ability of uterine tissues in rats with endometriosis during the implantation window, which could be an important cause of endometrial receptivity impairment in endometriosis. 


\section{Materials and methods}

Ethics statement. The present study was approved by the Experimental Animal Center of the Peking Union Medical College Hospital and Chinese Academy of Medical Sciences (permit no. XHDW-2016-000). All experiments were performed in accordance with the principles of experimental animal management and protection. The rats were humanely cared for and sacrificed to prevent suffering.

Experimental animals and collection of specimens. Clean, sexually mature and non-pregnant Sprague-Dawley female $(n=35)$ and male $(n=10)$ rats were selected. The age of the female rats was $60-70$ days and their weight was $200 \pm 10 \mathrm{~g}$. The weight of the male rats was $380 \pm 10 \mathrm{~g}$ (age, 60-70 days). All rats were purchased from Beijing Vital River Laboratory Animal Technology Co., Ltd., and they were kept in the specific pathogen-free facility of the Laboratory Animal Center of Peking Union Medical College Hospital. Room temperature was $20-25^{\circ} \mathrm{C}$ and relative humidity was $45-60 \%$. The rats were housed five per cage. All rats were kept under 14-h light/10-h dark cycle. They received sterilized feed and water ad libitum. They were adaptively fed for 2-3 days before experiments. The vaginal smear method was used to determine the estrous cycle of each female rat, which was usually 4-5 days.

The 35 female rats were divided into three groups: Endometriosis group ( $\mathrm{n}=13)$, adipose tissue control group $(n=8)$ and blank control group $(n=14)$. After the observation of three estrous cycles, the autologous transendocardial transplantation method described by Vernon and Wilson (12) was performed, but with slight improvements. In the endometriosis group, a segment of autologous uterine tissue was collected and transplanted onto the abdominal wall in the fourth estrus cycle. Pentobarbital sodium $(5 \%, 50 \mathrm{mg} / \mathrm{kg}$, i.p.) was used for anesthesia. The rats were placed in a supine position and the abdominal skin was prepared. A longitudinal abdominal incision $(5 \mathrm{~cm})$ was made to open the abdominal cavity and to find the Y-shaped uterus. The left uterine horn was lifted and uterine tissue $(1 \mathrm{~cm})$ was collected and quickly placed in a culture dish with saline water. The extra adipose tissues outside the serous layer were removed. A longitudinal incision of the uterine cavity was made and two pieces $(5 \times 5 \mathrm{~mm})$ were sutured on both sides of the abdominal wall at sites rich in blood vessels. Then the abdominal incision was sutured layer by layer.

In the adipose tissue control group, eight female rats were randomly selected. They underwent the same surgery as in the endometriosis group, but the left uterine horn was ligated and two pieces of adipose tissues $(5 \times 5 \mathrm{~mm})$ were collected from the abdomen and sutured onto both sides of the abdominal wall. In the blank control group, no surgery was performed.

A total of 28 days after operating, the rats in the endometriosis and adipose tissue groups were re-operated to observe the growth, invasion and adhesion of the transplanted endometrium. Growth of ectopic endometrium (the transplanted tissues were $5 \times 5 \mathrm{~mm}$ ), tissue edema (as a sign of inflammation) and vesicle formation were observed by the naked eye. The models were considered successful if the transplanted endometrium has grown by at least 2 -fold. The model success rate was calculated as the number of successful models divided by the total number of animals that underwent modeling. The scoring criteria of the ectopic uterine tissue growth were: Score 0, no epithelium; score 1, poorly preserved epithelium; score 2 , moderately preserved epithelium; and score 3 , well preserved epithelium $(13,14)$. The abdominal incision was sutured layer by layer. All rats survived and were prepared for mating.

A total of 10 male rats were kept in different cages. The female rats were placed in the cages with one male rat at 18:00 every night and a tray was placed under each cage. At 8:00-9:00 the next morning, the trays were checked for vaginal plugs and vaginal smear examinations were carried out. If a vaginal plug and sperm were observed under the microscope at the same time, it was considered to be the 1st day of pregnancy (D1) (15), and mating was not conducted anymore. On the 5th day of pregnancy (D5) [i.e., during the short implanting window; implantation occurs on day 5 in rats (15)], female rats were sacrificed to collect the uterine tissues. The tissues were divided into two parts. One part was put in $10 \%$ formalin at $4{ }^{\circ} \mathrm{C}$ for at least $24 \mathrm{~h}$ for subsequent hematoxylin and eosin (H\&E) staining and immunohistochemistry. The other part was quickly put into liquid nitrogen at $-80^{\circ} \mathrm{C}$ for gene chip analysis and reverse transcription-quantitative (RT-q)PCR. All experiments were performed using the samples from the same rats in each group.

RNA extraction. According to the manufacturer's protocol, TRIzol (Invitrogen; Thermo Fisher Scientific, Inc.) was used to extract the total RNA from the uterine tissues $(100 \mathrm{mg})$. RNA was purified using the mirVana miRNA Isolation kit (Ambion; Thermo Fisher Scientific, Inc.). RNA concentration and purity were determined by spectrophotometry (NanoDrop ND-1000; Thermo Fisher Scientific, Inc.) to measure optical density at 260/280 nm. The RNA 6000 Nano Lab-on-a-Chip kit and the Bioanalyzer 2100 (Agilent Technologies, Inc.) were used and RNA integrity was verified by electrophoresis on formaldehyde $(1 \%)$ gels. The tissues with RNA integrity $>6$ were selected for the subsequent experiments.

Microarray imaging and data analysis. Complementary(c) DNA was synthesized from $5 \mu 1$ total RNA. The GeeDom ${ }^{\circledR}$ biochip (CapitalBio Corp.) labeling kit was used. The Nucleospin ${ }^{\circledR}$ Extract II kit (Macherey-Nagel, GmbH) was used to purify the labeled products. The rat lncRNA+mRNA Array V1.0 (8x60K format, the sequence included 4,974 control probes; Agilent Technologies, Inc.) was used for hybridization. The probes in each sequence represented 22,020 rat lncRNAs and 30,254 rat mRNAs. These lncRNA and mRNA probes sequences referred to multiple databases including NCBI RefSeq (https://www.ncbi.nlm.nih.gov/refseq/), Ensembl (http://www.ensembl.org/index.html), UCSC genome browser (http://genome.ucsc.edu/), NONCODE V4.0 (http://www. noncode.org) and UCR (https://users.soe.ucsc.edu/ jill/ultra. html) (16). Each RNA is detected by the probe at least 1-2 times and each microarray includes 4,974 probes.

After hybridization, the chip was washed in the GeeDom ${ }^{\circledR}$ Slide Washer 8. The Agilent chip scanner (G2565CA) was used to scan the chip. The Agilent Feature Extraction (v10.7) software (Agilent Technologies, Inc.) was used to analyze the images. The GeneSpring software V13.0 (Agilent Technologies, Inc.) was used for the summary, standardization and quality 
control of chip data. Values of $\geq 2$ and $\leq-2$ fold-change, as well as $\mathrm{P}<0.05$ were used for screening for differentially expressed genes. CLUSTER 3.0 software (Stanford University) with data adjustment functions was used to perform the $\log 2$ conversion and median calculation of chip data. Finally, the Java Treeview v1.8 (Stanford University School of Medicine) was used for cluster analysis. The samples were tested in triplicates.

RT-qPCR validation of differentially expressed lncRNAs and $m R N A s$. The criteria for selecting the candidate differentially expressed genes for validation were: i) Fold-change was $\geq 2$; ii) the biological repeat of each group was $\geq 3$; and iii) $\mathrm{P} \leq 0.05$. For an upregulated gene, the number of samples with the detected flag of the experimental group was required to be $>60 \%$ of the total number of samples in the group. For a downregulated gene, the number of samples with the detected flag of the control group was required to be $>60 \%$ of the total number of samples in the group.

Therefore, according to bioinformatics, the relationship between the targeted regulation of the selected five IncRNAs and the mRNA microarray results (abnormal expression folds in the endometriosis group and the blank control group) were selected for four mRNAs [ADAM metallopeptidase with thrombospondin type 1 motif 7 (Adamts7), tumor protein p53 (Tp53), distal-less homeobox 3 (Dlx3) and pyrimidinergic receptor P2Y6 (P2ry6)] for qPCR validation.

The primers are shown in Table I. The FastQuant RT kit [Tiangen Biotech (Beijing) Co., Ltd.] was used for the reverse transcription of total RNA: $1 \mu \mathrm{g}$ total RNA and $20 \mu \mathrm{l}$ reaction system (10X Fast-RT Buffer $2 \mu \mathrm{l}$, FQ-RT Primer Mix $2 \mu \mathrm{l}$, RT Enzyme Mix $1 \mu \mathrm{l}$, RNase-Free water 5 and $10 \mu \mathrm{l}$ buffer) were kept at $42^{\circ} \mathrm{C}$ for $15 \mathrm{~min}, 95^{\circ} \mathrm{C}$ for $3 \mathrm{~min}$, cooled on ice and reverse transcribed. The same amount of RNA was used for all samples. The qPCR reaction system Power SYBR ${ }^{\circledR}$-Green PCR Master Mix (Applied Biosystems; Thermo Fisher Scientific, Inc.; $10 \mu \mathrm{l}$ ) containing Power SYBR ${ }^{\circledR}$-Green PCR Master Mix (2X) $5 \mu 1$, cDNA sample $0.5 \mu 1$, forward primer $(10 \mu \mathrm{M}, 0.25 \mu \mathrm{l})$, reverse primer $(10 \mu \mathrm{M}, 0.25 \mu \mathrm{l})$ and nuclease-free water $(4 \mu \mathrm{l})$ were used in a MicroAmp Optical 96-Well Reaction Plate (Applied Biosystems; Thermo Fisher Scientific, Inc.). Denaturation was carried out at $95^{\circ} \mathrm{C}$ for 10 min in a QuantStudio ${ }^{\text {TM }} 7$ Flex RealTime PCR system (Applied Biosystems; Thermo Fisher Scientific, Inc.). Then, 40 cycles $\left(95^{\circ} \mathrm{C}\right.$ for $15 \mathrm{sec}$ and $60^{\circ} \mathrm{C}$ for $\left.1 \mathrm{~min}\right)$ and a final extension at $60^{\circ} \mathrm{C}$ for $10 \mathrm{~min}$ were performed, before climbing up to $95^{\circ} \mathrm{C}$ for melting curve analysis (temperature ramp of $2 \%$ ). All RT-qPCR reactions were performed in triplicate. Electrophoresis (agarose gel, 2.0\%) was used to detect the amplification specificity of the products. GAPDH was selected as the internal reference gene. Expression was measured using the $2^{-\Delta \Delta \mathrm{Cq}}$ method (17).

Immunohistochemistry. The SP method was used for immunohistochemistry (18). All specimens were fixed in neutral formalin (10\%) for at least $24 \mathrm{~h}$ at room temperature, paraffin-embedded, sectioned $(4 \mu \mathrm{m})$ and dewaxed at $60^{\circ} \mathrm{C}$ overnight. Then, they were incubated in xylene for $45 \mathrm{~min}$, hydrated in decreasing ethanol series and washed with distilled water for $5 \mathrm{~min}$. After antigen retrieval, the slides were placed in PBS (pH 7.4), shaken and washed three times, 15 min each time. The sections were placed in hydrogen peroxide (3\%) to block endogenous peroxidase and incubated at room tempera-

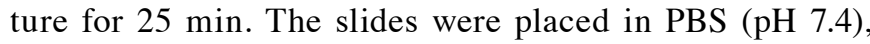
shaken and washed three times, 15 min each time. Bovine serum albumin (3\%) (Wuhan Servicebio Technology, Co., Ltd.) was added and incubated at room temperature for $30 \mathrm{~min}$. After adding antibodies against Adamts7 (1:200; cat. no. 250456; Abbiotec, Inc.), P2ry6 (1:50; cat. no. GTX16829; GeneTex, Inc.), Dlx3 (1:100; cat. no. 27-520; ProSci, Inc.) and Tp53 (1:200; cat. no. 70-527; ProSci, Inc.), the slides were incubated at $4^{\circ} \mathrm{C}$ in a wet box for the night. The DAKO K5007 rat/rabbit secondary antibody (cat. no. K5007; ready-to-use preparation; Dako; Agilent Technologies, Inc.) was added and incubated at room temperature for $50 \mathrm{~min}$. DAB coloration (cat. no. G1211; Wuhan Servicebio Technology, Co., Ltd.) was performed and stained with hematoxylin for $3 \mathrm{~min}$ at room temperature, before observation under a light microscope.

Protein extraction and western blotting. The frozen uterine tissues were homogenized in $5 \mathrm{X}$ protein loading buffer (G2013; Wuhan Servicebio Technology, Co., Ltd.) with phosphorylation protease inhibitor (G2007; Wuhan Servicebio Technology, Co., Ltd.), cooled on ice for $30 \mathrm{~min}$ and centrifuged at $13,000 \mathrm{x} \mathrm{g}$ for $10 \mathrm{~min}$ at $4^{\circ} \mathrm{C}$. The supernatant was kept. The bicinchoninic kit (Wuhan Servicebio Technology, Co., Ltd.) was used to determine protein concentration. The protein solution [mixed 4:1 with $5 \mathrm{X}$ protein sample buffer (Wuhan Servicebio Technology, Co., Ltd.)] was boiled for $15 \mathrm{~min}$ and stored at $-20^{\circ} \mathrm{C}$. Proteins $(30 \mu \mathrm{g})$ were separated using $10 \%$ SDS-PAGE. Proteins were transferred to polyvinylidene difluoride membranes, which were blocked with $5 \%$ skimmed milk for $1 \mathrm{~h}$ at room temperature. The primary antibodies against P2ry6 (1:1,000), Adamts7 (1:1,000), Dlx3 $(1: 1,000)$ and Tp53 (1:1,000; cat. no. orb319621; Biorbyt, Ltd.) were incubated at $4^{\circ} \mathrm{C}$ overnight. The membranes were washed in TBST (Tween-20, 0.05\%) three times at room temperature. The secondary antibody HRP-labeled goat anti rabbit (1:3,000; cat. no. GB23303; Wuhan Servicebio Technology, Co., Ltd.) was incubated at room temperature for $30 \mathrm{~min}$. The membranes were washed in TBST and enhanced chemiluminescence reagents A and B (cat. no. G2014; Wuhan Servicebio Technology, Co., Ltd.) was carried out. Adobe PhotoShop CS5 (Adobe Inc.) was used for image analysis. $\beta$-actin $(1: 3,000$; cat. no. GB12001; Wuhan Servicebio Technology, Co., Ltd.) was selected as internal reference. Grey value analysis (alphaEaseFC v4.0; Alpha Innotech Corporation) was carried out.

Functional prediction of IncRNAs and co-expression with mRNAs. As in a previous study (19), the Pearson correlation coefficient (PCC) between each abnormally expressed lncRNA and its co-expressed mRNA was calculated. PCC $>0.8$ or $<0.8$ and $\mathrm{P}<0.01$ represented significantly related lncRNA/mRNA. The hypergeometric cumulative distribution function was used to conduct functional enrichment analysis for co-expressed mRNA. The function of lncRNA was predicted through gene ontology (GO) (http://geneontology.org/) and Kyoto Encyclopedia of Genes and Genomes (KEGG) pathway analysis (http://www.genome.jp/kegg/). On this basis, protein regulatory genes could be predicted using cis and trans $(20,21)$. On the basis of the screening results of IncRNA and mRNA co-expression 
Table I. Primers for reverse transcription-quantitative PCR.

\begin{tabular}{|c|c|c|}
\hline Gene & Primers $\left(5^{\prime}-3^{\prime}\right)$ & Length \\
\hline \multirow[t]{2}{*}{ NONRATT003997 } & F: CAGGGTCGGGAAACTTTGAGA & $22 \mathrm{bp}$ \\
\hline & R: CATCCAGTGTCCAGTGAGGG & \\
\hline \multirow[t]{2}{*}{ gil672027621|ref|XR_592747.1l } & F: CACGGAATGACAAGTGTGGG & $104 \mathrm{bp}$ \\
\hline & R: GGTGACTAATTGCCCCCGTA & \\
\hline \multirow[t]{2}{*}{ gil672045999|ref|XR_591544.1| } & F: CAGCTGGATCTGCTTTCGGA & $127 \mathrm{bp}$ \\
\hline & R: AGGAGACCCCAGATAAGCCT & \\
\hline \multirow[t]{2}{*}{ NONRATT006252 } & F: ACATAGCATTGGGCCCTGTC & $134 \mathrm{bp}$ \\
\hline & R: TCTAAAAGTCTCAGAGCATTCTCAA & \\
\hline \multirow[t]{2}{*}{ gil672033904|ref|XR_589853.1l } & F: AAGGGTTGGGAAGACCATGAC & $120 \mathrm{bp}$ \\
\hline & R: GAGACTCCCTGCTCACTTACG & \\
\hline \multirow[t]{2}{*}{ Adamts7 } & F: TCAATTTCTGTGAGACGCTGC & $147 \mathrm{bp}$ \\
\hline & R: ATGGTGCGTGGGTTTATCGT & \\
\hline \multirow[t]{2}{*}{ Tp53 } & F: CCCCACCGCCTGTAAGATTC & $110 \mathrm{bp}$ \\
\hline & R: GAGGGGTGGGGGATGGATA & \\
\hline \multirow[t]{2}{*}{ Dlx3 } & F: TCAATCTCAATGGGCTCGCA & $90 \mathrm{bp}$ \\
\hline & R: GGTACGCTCCATACTGTCGG & \\
\hline \multirow[t]{2}{*}{ P2ry6 } & F: GGTAGCTTGAGGCTGAGAGG & $126 \mathrm{bp}$ \\
\hline & R: TGACAGAAGTGTGTACGGCAT & \\
\hline \multirow[t]{2}{*}{ GAPDH } & F: CCTCAAGATCATCAGCAAT & $141 \mathrm{bp}$ \\
\hline & R: CCATCCACAGTCTTCTGGGT & \\
\hline
\end{tabular}

Adamts7, ADAM metallopeptidase with thrombospondin type 1 motif 7; Tp53, tumor protein p53; Dlx3, distal-less homeobox 3; P2ry6, pyrimidinergic receptor P2Y6.

(correlation $>0.99$ or $<-0.99$ and $\mathrm{P}<0.05$ ), cis-prediction looked for lncRNA-mRNA pair whose genomic location was within $10 \mathrm{~kb}$ and trans-prediction used Blat (http://hgdownload.cse. ucsc.edu/admin/exe/) to compare IncRNA and mRNA (3'UTR) sequences, and selected lncRNA-mRNA pair that had similar sequence and beyond $100 \mathrm{~kb}$ distance.

Statistics analysis. The tiff image data after hybrid scanning of the Gem ${ }^{\circledR}$ IncRNA+mRNA expression spectrum chip was preprocessed by the Feature Extraction software v10.7 (Agilent Technologies, Inc.). The GeneSpring GX software v13.0 (Agilent Technologies, Inc.) was used to calculate the differences of gene expression and statistical significance (P-value). Continuous data (such as the RT-qPCR data) were expressed as the mean \pm standard deviation and analyzed using analysis of variance with post hoc Tukey's test. The Fisher's exact test was used to analyze GO and KEGG data. The PCC was used to calculate the co-expression relationship between lncRNA and mRNA. SPSS 19.0 (IBM, Corp.) was used to conduct statistical analysis. $\mathrm{P}<0.05$ was considered to indicate a statistically significant difference.

\section{Results}

Endometriosis modeling was successful. On the 28th day after surgery, growth of ectopic endometrium of the transplanted tissues was $5 \times 5 \mathrm{~mm}$, tissue edema (a sign of inflammation) and vesicle formation (Fig. 1A) were observed. All rats in the endometriosis group were scored 3 with well-preserved epithelium H\&E staining showed that endometrial glands developed (Fig. 1B). In the adipose tissue control group, there was no change in the transplant (Fig. 1C) and H\&E staining showed no endometrial glands (Fig. 1D). The abdominal walls of rats in the blank control group were normal. According to observation and H\&E staining, the success rate of the endometrial transplantation modeling was $100 \%$.

Endometriosis is associated with differentially expressed lncRNAs. Compared with the blank control group, the endometriosis model group showed 166 differentially expressed lncRNAs: 115 upregulated and 51 downregulated (fold-change $>2$ ) (Fig. 2A and Tables II and III).

In order to confirm the results of the gene chip analysis, three IncRNAs with upregulated expression (gil672027621|refIXR_592747.1I, NONRATT006252 and gil672045999|reflXR_591544.1I) and two lncRNAs with downregulated expression were selected for RT-qPCR validation. The expression trend and amplitude were consistent with the results of the gene chip analysis (Fig. 2B).

gil672066614|reflXR_594547.1 (LOC103693263) was the most upregulated lncRNA [fold-change $(\mathrm{FC})=5.35 ; \mathrm{P}<0.01$ ] (Tables II and III, and Fig. 3). NONRATT006252 (FC=3.42; $\mathrm{P}<0.01)$ and gil672045999|ref|XR_591544.1I $(\mathrm{FC}=2.88, \mathrm{P}<0.01)$ were also significantly upregulated (Tables II and III, and Fig. 3).

NONRATT003997 was the most significantly downregulated (absolute FC=10.95; P<0.01) (Tables II and III, and Fig. 3). gil672033904|reflXR_589853.1l was also significantly downregulated (absolute FC=5.79; P<0.01) (Tables II and III, and Fig. 3). 
28 days post-operation
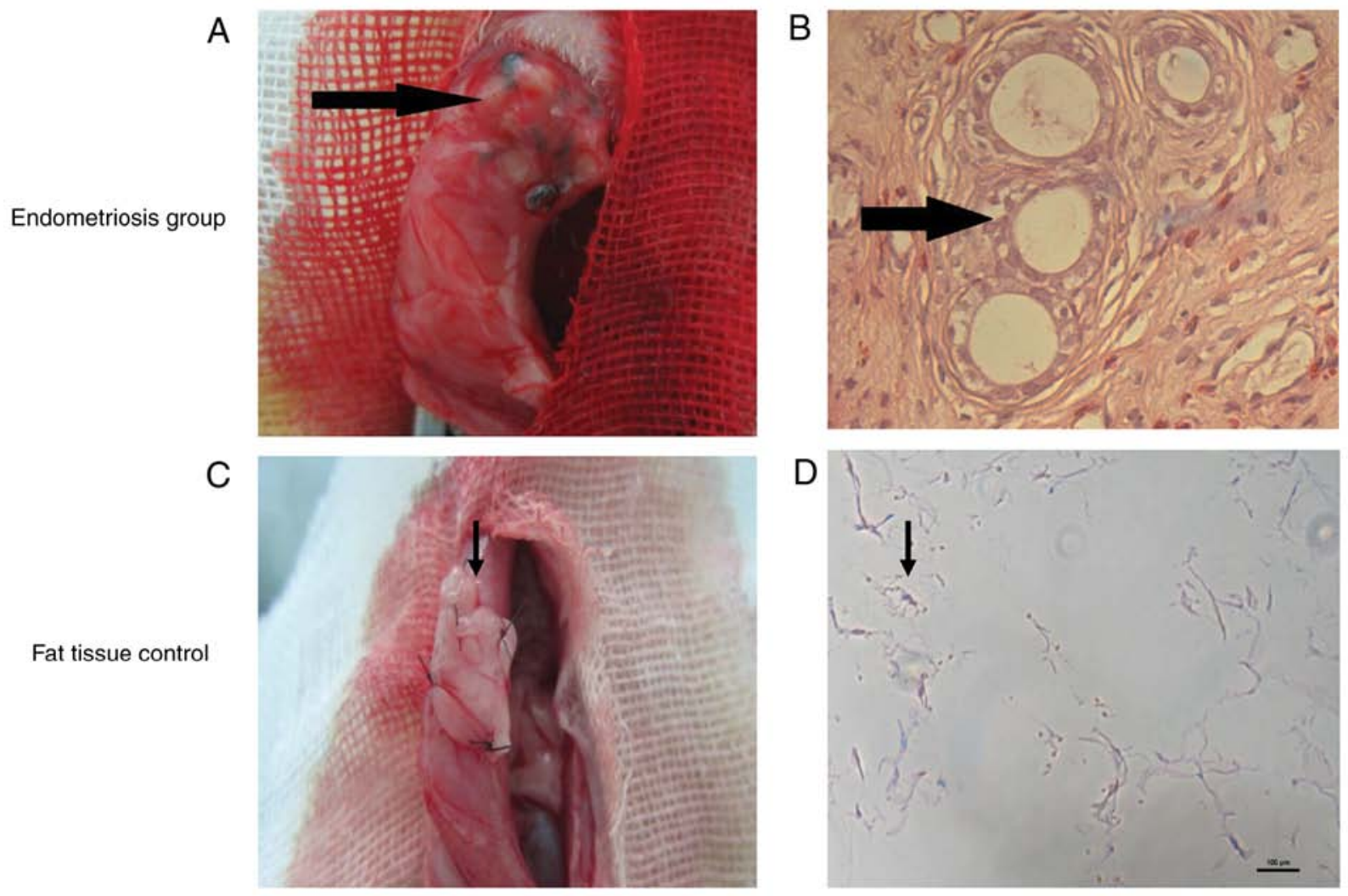

Figure 1. Endometriosis modeling is successful. (A) Volume growth, tissue edema and vesicle formation were observed in the endometriosis group. The arrow shows uterine tissue transplantation. (B) H\&E staining showed that endometrial glands were developed in the endometriosis group ( $\mathrm{n}=13$ ). The arrow shows an endometrial gland. (C) In the adipose tissue control group $(n=8)$, there was no change in the transplant. The arrow shows adipose tissue transplantation. (D) H\&E staining showed no endometrial glands in the adipose tissue control group. Scale bar $100 \mu \mathrm{m}$. The arrow show adipocytes. HE, hematoxylin and eosin.
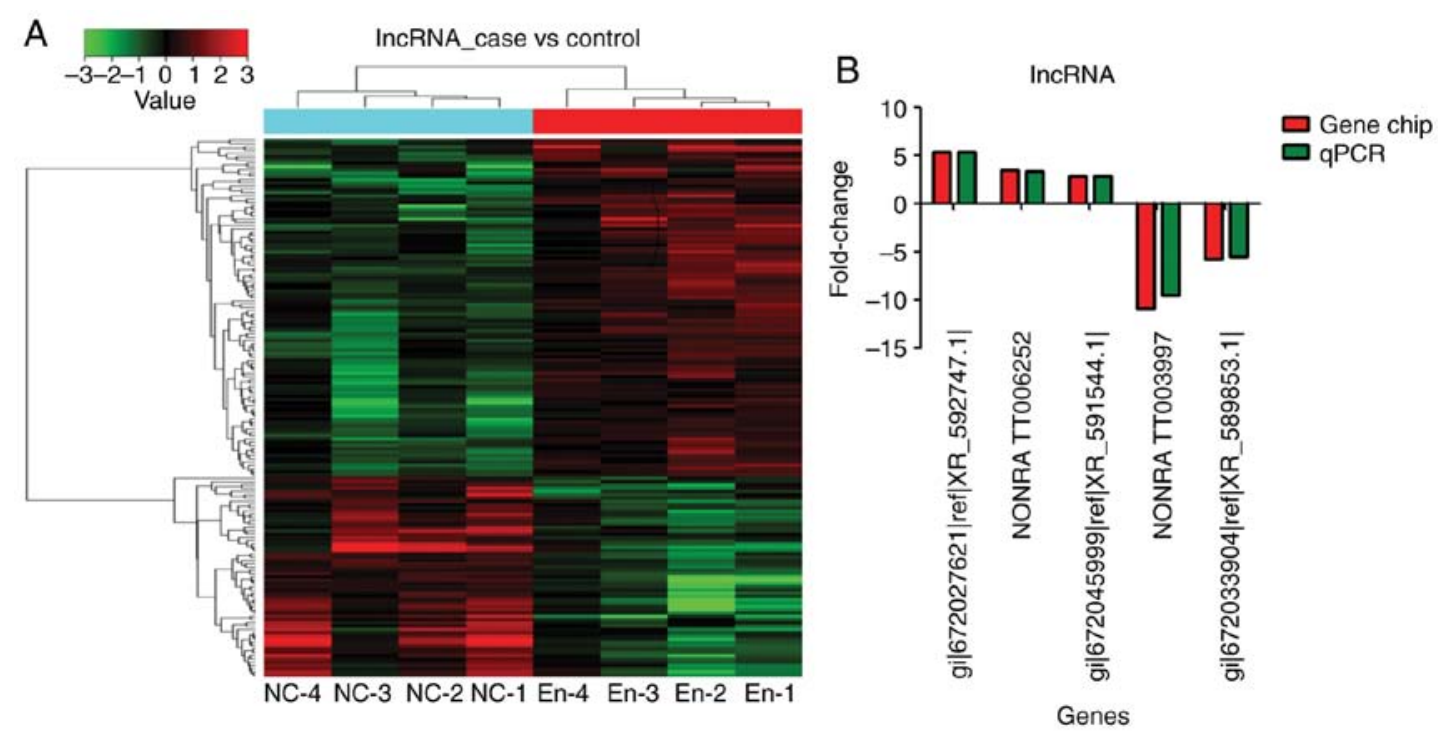

Figure 2. Compared with the blank control group $(n=4)$, the endometriosis model group $(n=4)$ shows 166 differentially expressed lncRNAs: 115 upregulated and 51 downregulated (fold-change $>2$ ). (A) Gene chip analysis. (B) Reverse transcription-quantitative PCR confirmation using five lncRNAs. The samples were tested in triplicates. lnc, long noncoding.

Endometriosis is associated with differentially expressedmRNAs. Overall, 182 mRNA transcripts were differentially expressed: 97 were upregulated and 85 were downregulated (fold-change $>2$ ) (Fig. 4A). According to bioinformatics, four mRNAs (Adamts7,
Tp53, Dlx3 and P2ry6) were selected in the prediction of target regulation relationship with five lncRNAs and gene chip results. RT-qPCR validation showed that the expression of those mRNA was consistent with the gene chip analysis (Fig. 4B). 
Table II. Top 20 upregulated lncRNA.

\begin{tabular}{|c|c|c|c|}
\hline lncRNA (probe name) & $\mathrm{FC}(\mathrm{abs})$ & P-value & lncRNA (name) \\
\hline gil672066614|ref|XR_594547.1I & 5.34641 & 0.00327 & LOC103693263 \\
\hline gil672076298|ref|XR_595802.1। & 4.895411 & 0.02629 & LOC103693752 \\
\hline gil672079914|ref|XR_360377.2l & 4.506577 & 0.032437 & LOC102548312 \\
\hline gil672036138|ref|XR_590129.1। & 3.46012 & 0.001325 & LOC103691084 \\
\hline NONRATT018493 & 3.433898 & 0.008362 & \\
\hline NONRATT006252 & 3.42446 & 0.01579 & \\
\hline NONRATT020400 & 3.267124 & 0.019514 & \\
\hline NONRATT021467 & 3.102348 & 0.007103 & \\
\hline NONRATT025682 & 3.051757 & 0.00634 & \\
\hline NONRATT030954 & 3.017166 & 0.011163 & \\
\hline NONRATT011228 & 3.015996 & 0.002754 & \\
\hline NONRATT027460 & 2.978006 & 0.018386 & \\
\hline gil672045999|ref|XR_591544.1| & 2.87815 & 0.01452 & LOC103691820 \\
\hline NONRATT012251 & 2.869275 & 0.01117 & \\
\hline NONRATT016194 & 2.819013 & 0.038048 & \\
\hline NONRATT010960 & 2.785293 & 0.022526 & \\
\hline gil672052626|ref|XR_592505.1| & 2.765093 & 0.006744 & LOC103692352 \\
\hline gil672020316lref|XR_346989.2I & 2.726432 & 0.001031 & LOC102548283 \\
\hline gil672037438|ref|XR_590367.1। & 2.619791 & 0.00196 & \\
\hline NONRATT028550 & 2.596784 & 0.019415 & \\
\hline
\end{tabular}

lnc, long noncoding; abs, absolute.

Adamts7 (A_44_P964460; FC $=3.75, \mathrm{P}<0.01$ ) and P2ry6 (A_64_P042495; FC $=7.37 ; \mathrm{P}<0.05$ ) were among the first 20 upregulated mRNAs (Tables IV and V and Fig. 5). Dlx3 was the second downregulated mRNA [FC absolute (ABS)=7.79; $\mathrm{P}<0.05]$ Tables IV and V, and Fig. 5). Tp53 was among the first 20 downregulated mRNAs [FC $(\mathrm{ABS})=5.01, \mathrm{P}<0.01$ ] (Tables IV and V and Fig. 5).

Adamts 7 and $P 2 r y 6$ proteins are differentially expressed in endometriosis, but not Dlx 3 and Tp53. Validation was performed using samples from 13 rats in the endometriosis group, eight in the adipose tissue control group and 14 in the blank control group. Fig. 6A shows that Adamts7 was expressed in the uterine tissues of all three groups during the implantation stage, mainly in the endometrial stroma, glands and uterine cavity epithelium. The expression in the endometriosis group was upregulated significantly in comparison with the two control groups (adipose tissue and blank controls) in the three types of tissues $(\mathrm{P}<0.05)$. The Adamts7 expression was significantly increased in the adipose tissue control group compared with in the blank control group in uterine stroma and glandular epithelium $(\mathrm{P}<0.05$; Fig. 6B).

P2ry6 was expressed in the uterine tissues of all three groups of rats during the implantation stage, mainly in the endometrial stroma, glands and uterine cavity epithelium. The expression of P2ry6 was significantly increased in the endometriosis group compared with in the two control groups in the three tissue types $(\mathrm{P}<0.05)$. The expression of P2ry6 was also significantly increased in the adipose tissue control group compared with in the blank control group in uterine epithelium and stroma ( $\mathrm{P}<0.05$; Fig. 6C).

Dlx3 was expressed in the uterine tissues of all three groups of rats, mainly in the endometrial stroma and uterine cavity epithelium. The expression in the glands was relatively weak. In the endometrial stroma and uterine epithelium, there was no significant difference in Dlx 3 expression between the endometriosis and adipose tissue control groups $(\mathrm{P}=0.291$ and $\mathrm{P}=0.98)$, and the expression in the endometriosis and adipose tissue control groups was significantly downregulated in comparison with the blank control group $(\mathrm{P}<0.05)$. There were no significant differences in the expression of Dlx 3 in the uterine glandular epithelium among the three groups ( $\mathrm{P}=0.80$; Fig. $6 \mathrm{D})$.

$\mathrm{Tp} 53$ was expressed in the uterine tissues of all three groups of rats, mainly in the endometrial stroma and uterine cavity epithelium. In all three tissue types, there was no significant difference in Tp53 expression between the endometriosis and adipose tissue control groups $(\mathrm{P}=0.089)$ and the expression the endometriosis and adipose tissue control groups was significantly downregulated in comparison with the blank control group $(\mathrm{P}<0.05$; Fig. 6E).

Taken together, those results suggest that endometriosis is associated with increased protein expression of Adamts7 and P2ry6, while Dlx 3 and Tp53 are not changed by endometriosis. Changes in Dlx3 and Tp53 protein expression could be due to the surgery.

Western blot analysis. Adamts7 was significantly upregulated in the endometriosis group in comparison with the adipose tissue control group $(\mathrm{P}=0.002)$ and blank control group $(\mathrm{P}=0.003)$, and its expression in the adipose tissue 

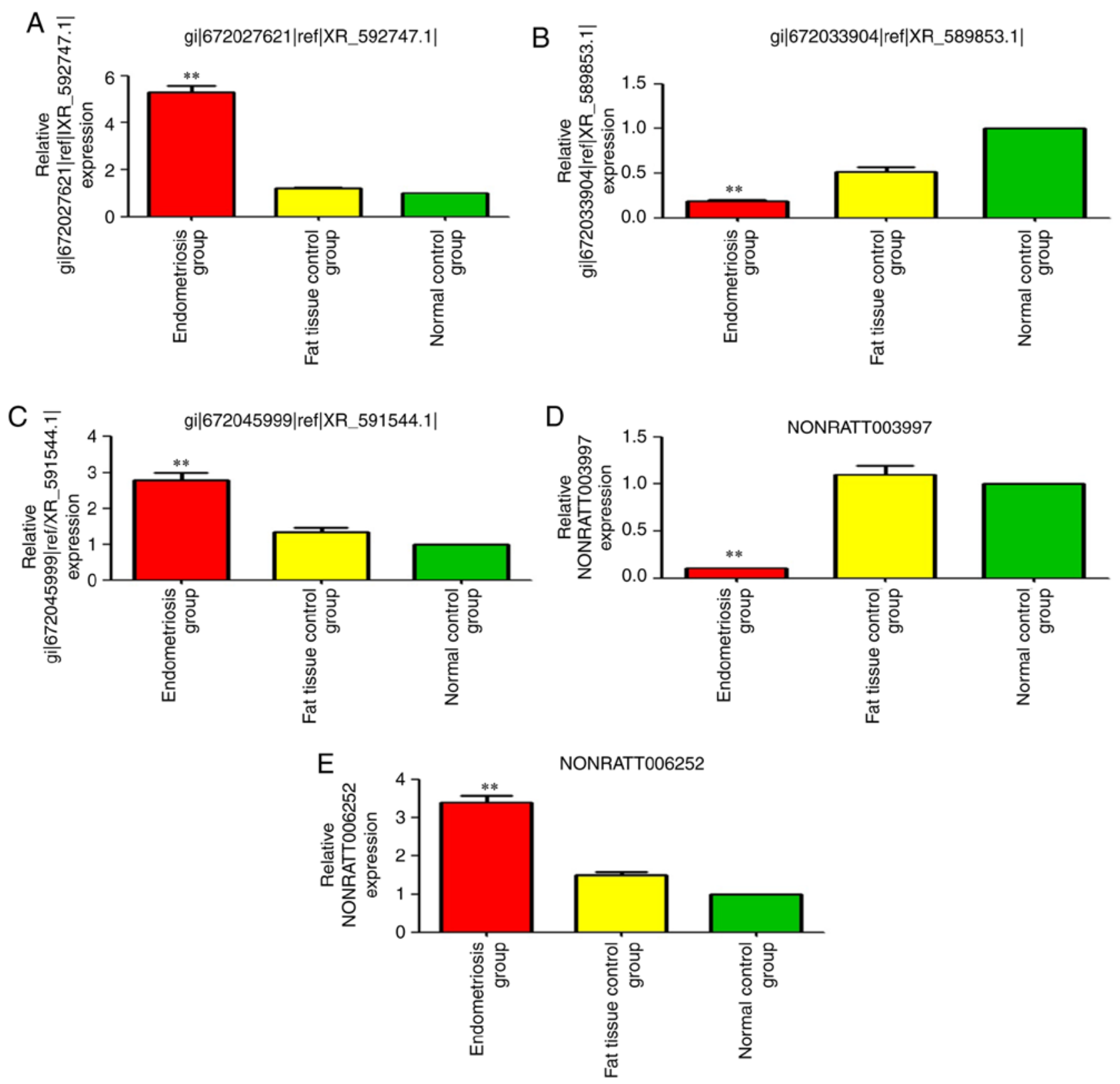

Figure 3. Changes in the expression of the five differentially expressed lncRNAs among the three groups. (A) gil672027621|reflXR_592747.11, (B) gil672033904| ref|XR_589853.1, (C) gil672045999|ref|XR_591544.11,(D) NONRATT003997 and (E) NONRATT006252. "* P<0.01 vs. the normal control. Inc, long noncoding.

control group was significantly upregulated compared with the blank control group $(\mathrm{P}=0.004$; Fig. 7A and $\mathrm{B})$. The expression of P2ry6 in the endometriosis group was significantly upregulated compared with the adipose tissue control group $(\mathrm{P}=0.001)$ and blank control group $(\mathrm{P}=0.001)$, and its expression in the adipose tissue control group was significantly increased compared with in the blank control group ( $\mathrm{P}=0.004$; Fig. 7A and $\mathrm{C}$ ). The expression of TP53 in the adipose tissue control group was significantly downregulated. compared with the blank control group $(\mathrm{P}=0.004$; Fig. 7A and E). The expression of Dlx 3 in the endometriosis group was significantly downregulated compared with the adipose tissue control group $(\mathrm{P}=0.002)$ and blank control group ( $\mathrm{P}=0.002)$; its expression in the adipose tissue control group was significantly downregulated compared with the blank control group ( $\mathrm{P}=0.002$; Fig. 7A and D). Taken together, those results show that the Adamts 7 and P2ry6 proteins are upregulated by endometriosis, while D1x3 and Tp53 are downregulated (Fig. 7).

$G O$ and KEGG analysis. In the GO pathway analysis, the mRNAs that were abnormally expressed were mainly involved in cell differentiation, response to oxygen-containing compounds, ureteric bud morphogenesis, ureter maturation, embryonic organ morphogenesis, endocrine hormone secretion, female pregnancy, the immune response, response to steroid hormones, the ER-nucleus signaling pathway, parturition, response to oxidative stress, reproductive processes, response to estrogen, regulation of reproductive processes, in utero embryonic development and placenta development (Table VI).

In the KEGG analysis (Fig. 8), differentially expressed mRNAs were mainly involved in estrogen signaling pathway, GnRH signaling pathway, inflammatory mediator regulation of TRP channels, endometrial cancer, ovarian steroidogenesis, 
Table III. Top 20 downregulated lncRNA.

\begin{tabular}{|c|c|c|c|}
\hline lncRNA (probe name) & $\mathrm{FC}(\mathrm{abs})$ & P-value & IncRNA (name) \\
\hline NONRATT003997 & 10.9511 & 0.00237 & \\
\hline NONRATT024485 & 10.62082 & 0.018243 & \\
\hline NONRATT009394 & 9.938666 & 0.044736 & \\
\hline gil672086757|ref|XR_597443.1l & 8.693425 & 0.014136 & LOC103694443 \\
\hline NONRATT016350 & 8.277449 & 0.007646 & \\
\hline NONRATT001658 & 7.982786 & 0.002575 & \\
\hline NONRATT005792 & 6.014078 & 0.00994 & \\
\hline gil672033904|ref|XR_589853.1I & 5.79144 & 0.01007 & LOC102546604 \\
\hline NONRATT014091 & 5.124274 & 0.014968 & \\
\hline gil672040874|ref|XR_590738.1I & 4.626765 & 0.018434 & LOC103691378 \\
\hline uc. 340 & 3.967024 & 0.00138 & \\
\hline NONRATT011360 & 3.901989 & 0.002246 & \\
\hline gil672030085|ref|XR_598174.1I & 3.857016 & 0.017871 & LOC102553701 \\
\hline gil672060549|ref|XR_355981.2l & 3.720889 & 0.007524 & LOC102547634 \\
\hline NONRATT003965 & 3.631949 & 0.001985 & \\
\hline gil672027547|ref|XR_592687.1I & 3.62932 & 0.002161 & LOC102547023 \\
\hline gil672034604|ref|XR_589986.1I & 3.453335 & 0.00527 & LOC103690992 \\
\hline NONRATT003634 & 3.397446 & 0.014216 & \\
\hline NONRATT018412 & 3.134341 & 0.015503 & \\
\hline gil672027788|ref|XR_340220.2I & 3.128051 & 0.010927 & LOC 102551595 \\
\hline
\end{tabular}

lnc, long noncoding; abs, absolute.

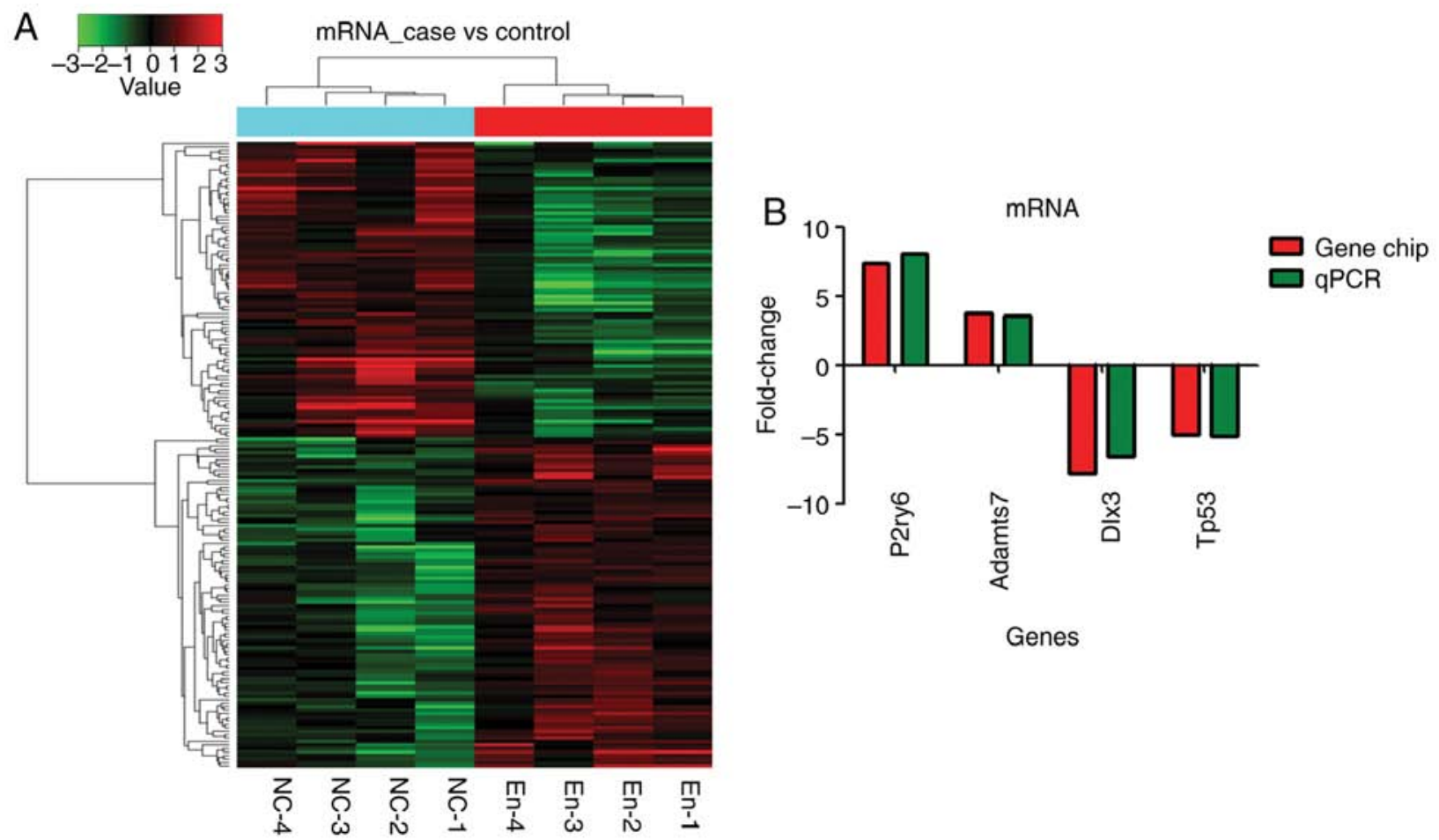

Figure 4. Compared with the blank control group $(n=4)$, the endometriosis model group $(n=4)$ shows that 182 mRNA transcripts were different: 97 were upregulated and 85 were downregulated (fold-change >2). (A) Gene chip analysis. (B) Reverse transcription-qPCR confirmation using four mRNAs. The samples were tested in triplicates. q, quantitative.

steroid hormone biosynthesis, apoptosis signaling pathway, insulin/IGF pathway-mitogen activated protein kinase/MAP kinase cascade, inflammation mediated by chemokine and cytokine signaling pathway. 
Table IV. Top 20 upregulated mRNA.

\begin{tabular}{llll}
\hline Probe name & \multicolumn{1}{c}{ mRNA } & FC (abs) & P-value \\
\hline A_64_P366031 & Cbln1 & 7.464442 & 0.002725 \\
A_64_P042495 & P2ry6 & 7.37147 & 0.02699 \\
A_64_P066251 & Ms4a14 & 5.004323 & 0.026015 \\
A_64_P021845 & Tac3 & 4.34276 & 0.024744 \\
A_44_P241448 & LOC102550973 & 3.948064 & 0.022094 \\
A_64_P057276 & LOC102549073 & 3.933694 & 0.023946 \\
A_42_P817214 & Efcab3 & 3.786581 & 0.004338 \\
A_44_P964460 & Adamts7 & 3.75427 & 0.01493 \\
A_44_P506980 & Pou3f4 & 3.655452 & 0.008571 \\
A_64_P044628 & Agtr1b & 3.09492 & 0.017631 \\
A_64_P012957 & Dntt & 3.094423 & 0.014797 \\
A_64_P016978 & Zfp488 & 3.061541 & 0.003415 \\
A_64_P087831 & Galnt13 & 3.038959 & 0.005398 \\
A_44_P135990 & Cd3g & 2.947655 & 0.002446 \\
A_64_P071732 & Lrrc4c & 2.944548 & 0.01782 \\
A_44_P375658 & Nxph1 & 2.943451 & 0.002413 \\
A_44_P1071620 & Sit1 & 2.608929 & 0.006022 \\
A_64_P059820 & Xkr6 & 2.532615 & 0.013807 \\
A_64_P003997 & Igsf1 & 2.527809 & 0.023865 \\
A_64_P113401 & Fam183b & 2.519156 & 0.00364 \\
\hline Abs,abs014te. & & & \\
\hline
\end{tabular}

Abs, absolute.

In unsupervised hierarchical clustering analysis, the differentially expressed lncRNA (Fig. 2A) and mRNA (Fig. 4A) were used to generate heat maps, and they segregated into the endometriosis group and the normal control group clusters.

lncRNA and mRNA co-expression profiles and lncRNA function prediction. Numerous IncRNA bind thousands of mRNA to achieve their biological functions. One lncRNA can bind to multiple mRNAs and one mRNA might be the target gene for multiple lncRNAs. For example, as shown in this study, Dlx3 was targeted by 32 lncRNA, TP53 was targeted by 35 lncRNA, P2ry6 was targeted by 33 lncRNA, Adamts 7 was targeted by 40 lncRNA, NONRATT003997 targeted 21 mRNA, gil672027621/reflXR_592747.1l targeted 23 mRNA, gil672045999|reflXR_591544.1l targeted 29 mRNA, NONRATT006252 targeted 24 mRNA, and gil672033904|reflXR_589853.1l targeted 32 mRNA (Tables VI and V). Taken together, these results indicate that the effect of endometriosis on uterine lncRNA and mRNA is complex (Table VII and Fig. 9).

\section{Discussion}

The present study showed that there were 115 upregulated lncRNAs, 51 downregulated lncRNAs, 97 upregulated mRNAs and 85 downregulated mRNAs in the uterine tissues of rats with endometriosis, compared with the control group. The relative protein expression levels of Adamts7, P2ry6, Dlx3 and TP53 were different in the endometriosis group. Bioinformatics could predict the co-expression relationship of
Table V. Top 20 downregulated mRNA.

\begin{tabular}{llcc}
\hline Probe name & \multicolumn{1}{c}{ mRNA } & FC (abs) & P-value \\
\hline A_64_P009530 & LOC687483 & 8.781071 & 0.003707 \\
A_44_P575055 & Dlx3 & 7.794150 & 0.014970 \\
A_64_P142988 & Fosb & 7.026777 & 0.029057 \\
A_44_P295042 & Cxcl5 & 6.987926 & 0.012344 \\
A_64_P094855 & Slc46a2 & 5.017081 & 0.002092 \\
A_64_P121136 & Tp53 & 5.013210 & 0.008090 \\
A_43_P11576 & Hspa1b & 4.539404 & 0.024537 \\
A_64_P043411 & Elf3 & 4.520617 & 0.006673 \\
A_42_P576446 & Krt17 & 4.418501 & 0.019014 \\
A_64_P062413 & Calml3 & 4.182893 & 0.004898 \\
A_64_P017515 & Ppp1r35 & 3.717559 & 0.014440 \\
A_64_P014090 & Grp & 3.703025 & 0.028939 \\
A_44_P271658 & LOC100912449 & 3.625274 & 0.008212 \\
A_64_P072638 & Jsrp1 & 3.393673 & 0.006873 \\
A_64_P124621 & LOC102555023 & 3.319351 & 0.006541 \\
A_64_P135713 & Mbnl3 & 3.274797 & 0.010593 \\
A_64_P113635 & RGD1563753 & 3.230319 & 0.005243 \\
A_64_P031497 & Murc & 3.213777 & 0.013858 \\
A_44_P107653 & Lrrc26 & 2.927319 & 0.027704 \\
A_64_P002809 & Tubb4a & 2.853953 & 0.008596 \\
\hline
\end{tabular}

the selected five lncRNAs and four mRNAs. GO and KEGG analyses predicted that Adamts7, P2ry6, D1x3, and TP53 were involved in endometriosis-related inflammation and reproductive pathways. Taken together, the results strongly suggest that the changes in the expression of lncRNAs, mRNAs and Adamts7, P2ry6, Dlx3 and TP53 proteins may possibly affect endometrial receptivity in rats with endometriosis during the implantation window.

Wang et al (7) found that the co-expression relationship of lncRNA(HOX)A11-AS1 (HOXA11 antisense RNA) and homeobox A (HOXA9, HOXA10, HOXA11 and HOXA13) played an important role in the pathogenesis of abdominal wall endometriosis. Powell et al (22) served the association among the allele 1p36.12 of LINC00339, blood CDC42 and endometriosis. Sun et al (9) found that 948 lncRNA transcripts and 4,088 mRNA transcripts were abnormally expressed in the ectopic endometrium of patients with endometriosis using gene chip technology. Ghazal et al (5) confirmed that H19 acted as a molecular sponge and attenuated the bioactivity of let-7 in the eutopic endometrium of patients with endometriosis; the expression of $\mathrm{H} 19$ in the endometrium of patients with endometriosis was significantly downregulated compared with those without endometriosis. Sigurgeirsson et al (23) found that the expression of 3,297 mRNAs, 516 lncRNAs and 102 small non-coding RNAs in the endometrium were significantly different between the proliferative phase and secretory phase of women's normal menstrual cycle (7-9 days after ovulation), and they speculated that the changes in the expression level of lncRNAs and mRNAs were probably the reasons for impaired endometrial receptivity. Shin et al (24) found that in the four-cell stage of embryo development in 
Table VI. GO analysis of mRNA.

\begin{tabular}{lrrr}
\hline Term & ID & Background number & P-value \\
\hline Reproduction & GO:0000003 & 715 & 0.934613717 \\
Steroid metabolic process & GO:0008202 & 205 & 0.907802417 \\
Embryo development ending in birth or egg hatching & GO:0009792 & 519 & 0.907802417 \\
Sexual reproduction & GO:0019953 & 543 & 0.828851221 \\
Placenta development & GO:0001890 & 127 & 0.809271211 \\
Steroid biosynthetic process & GO:0006694 & 115 & 0.785775079 \\
Embryonic epithelial tube formation & GO:0001838 & 105 & 0.767818727 \\
In utero embryonic development & GO:0001701 & 321 & 0.720657678 \\
Regulation of hormone secretion & GO:0046883 & 196 & 0.706512715 \\
Blastocyst development & GO:0001824 & 66 & 0.655993287 \\
Embryonic heart tube development & GO:0035050 & 64 & 0.648745020 \\
Maternal process involved in female pregnancy & GO:0060135 & 59 & 0.632235095 \\
Embryo development & GO:0009790 & 780 & 0.605305219 \\
Response to estrogen & GO:0043627 & 231 & 0.572555551 \\
Multicellular organismal reproductive behavior & GO:0033057 & 25 & 0.453156618 \\
Hormone transport & GO:0009914 & 253 & 0.437730680 \\
Chronic inflammatory response & GO:0002544 & 22 & 0.432311123 \\
Regulation of inflammatory response to antigenic stimulus & GO:0002861 & GO:0007567 & 17 \\
Parturition & GO:0060065 & 16 & 0.411517366 \\
Uterus development & & 0.389834482 \\
\hline
\end{tabular}

GO, gene ontology.
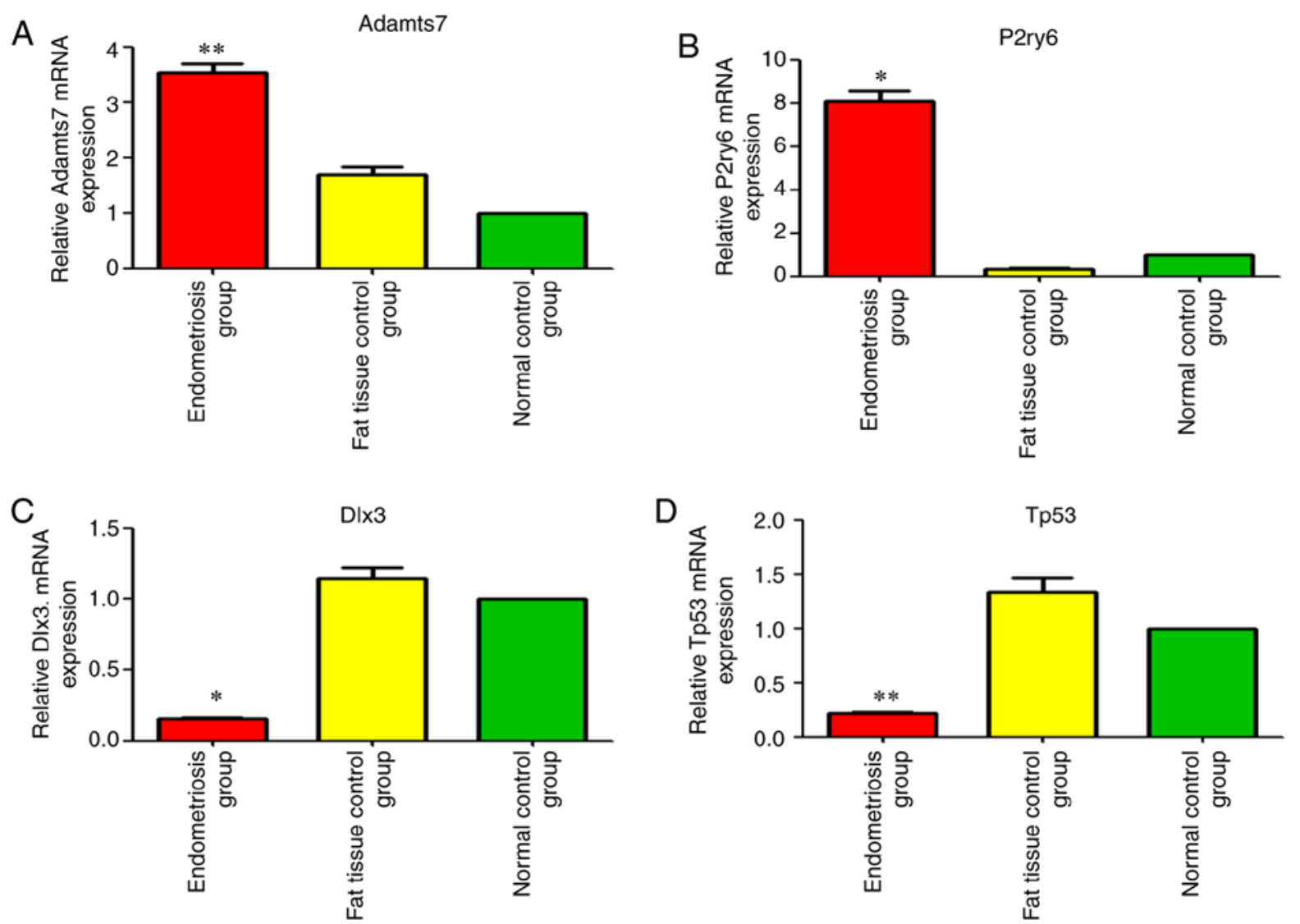

Figure 5. Changes in the expression of the four differentially expressed mRNAs among the three groups. mRNA expression of (A) Adamts7, (B) P2ry6 (C) Dlx3 and (D) Tp53. "P $<0.05$ and ${ }^{* *} \mathrm{P}<0.01$ vs. the normal control. Adamts7, ADAM metallopeptidase with thrombospondin type 1 motif 7; Tp53, tumor protein p53; Dlx3, distal-less homeobox 3; P2ry6, pyrimidinergic receptor P2Y6. 

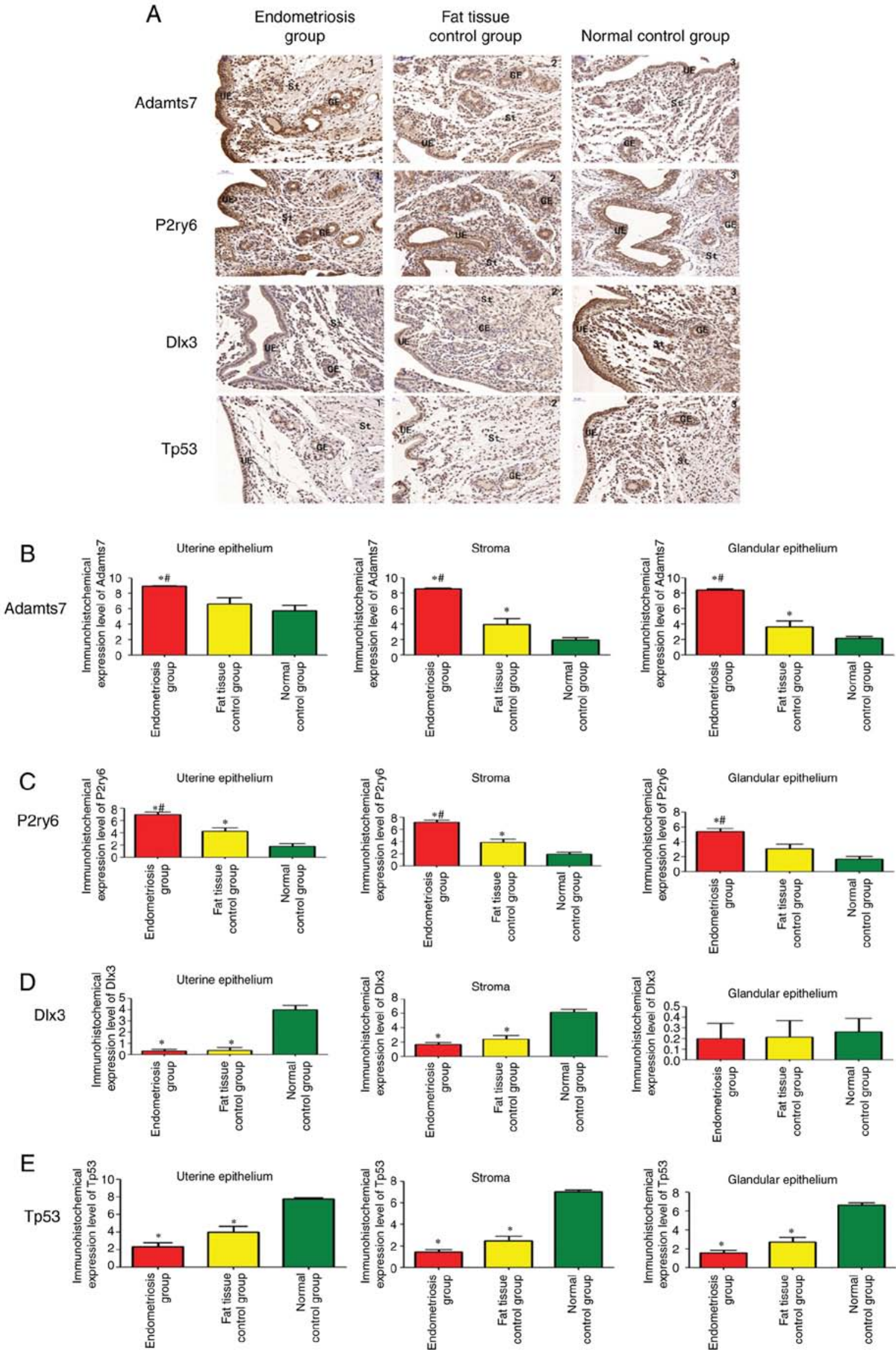

Figure 6. Immunohistochemistry of uterine tissue in rats. (A) Expression of Adamts7, P2ry6, D1x3 and Tp53 in the endometriosis group (n=13), adipose tissue control group ( $\mathrm{n}=8$ ) and blank control group $(\mathrm{n}=14)$. (magnification, $\mathrm{x} 200)$. Quantification of the immunohistochemistry results for (B) Adamts7, (C) P2ry6, (D) Dlx 3 and (E) Tp53. The samples were tested in triplicates. ${ }^{*} \mathrm{P}<0.05$ vs. blank controls. ${ }^{~} \mathrm{P}<0.05$ vs. adipose tissue controls. Adamts7, ADAM metallopeptidase with thrombospondin type 1 motif 7; Tp53, tumor protein p53; Dlx3, distal-less homeobox 3; P2ry6, pyrimidinergic receptor P2Y6; GE, glandular epithelium; St, endometrial stroma; UE, uterine epithelium. 
Table VII. Expression of lncRNA and mRNA.

\begin{tabular}{|c|c|c|c|c|c|}
\hline Source & Target & Correlation & P-value & Source gene symbol & Target gene symbol \\
\hline gil672033904|reflXR_589853.1I & A_64_P135713 & 0.992091 & 0.000001 & gil672033904 & Dlx3 \\
\hline NONRATT003997 & A_64_P135713 & 0.928748 & 0.000857 & - & Dlx3 \\
\hline gil672027621|reflXR_592747.1I & A_64_P135713 & -0.92396 & 0.001037 & gil672027621 & Dlx3 \\
\hline gil672033904|reflXR_589853.1I & A_64_P113635 & 0.961171 & 0.000142 & gil672033904 & Tp53 \\
\hline NONRATT003997 & A_64_P113635 & 0.96782 & 0.000081 & - & Tp53 \\
\hline gil672045999|reflXR_591544.1I & A_64_P113635 & -0.91168 & 0.00161 & gil672045999 & Tp53 \\
\hline NONRATT006252 & A_42_P814235 & 0.957719 & 0.000183 & - & P2ry6 \\
\hline gil672027621|reflXR_592747.1I & A_42_P814235 & 0.919696 & 0.001218 & gil672027621 & P2ry6 \\
\hline gil672045999|reflXR_591544.1I & A_42_P814235 & 0.919036 & 0.001248 & gil672045999 & P2ry6 \\
\hline gil672033904|reflXR_589853.1I & A_44_P178519 & -0.95751 & 0.000186 & gil672033904 & Adamts7 \\
\hline NONRATT006252 & A_44_P178519 & 0.912129 & 0.001586 & - & Adamts7 \\
\hline NONRATT003997 & A_44_P178519 & -0.9136 & 0.00151 & - & Adamts7 \\
\hline gil672027621|reflXR_592747.1I & A_44_P178519 & 0.921091 & 0.001157 & gil672027621 & Adamts7 \\
\hline gil672045999|reflXR_591544.1I & A_44_P178519 & 0.944424 & 0.000411 & gil672045999 & Adamts7 \\
\hline
\end{tabular}

lnc, long noncoding; Adamts7, ADAM metallopeptidase with thrombospondin type 1 motif 7; Tp53, tumor protein p53; Dlx3, distal-less homeobox 3; P2ry6, pyrimidinergic receptor P2Y6.

A

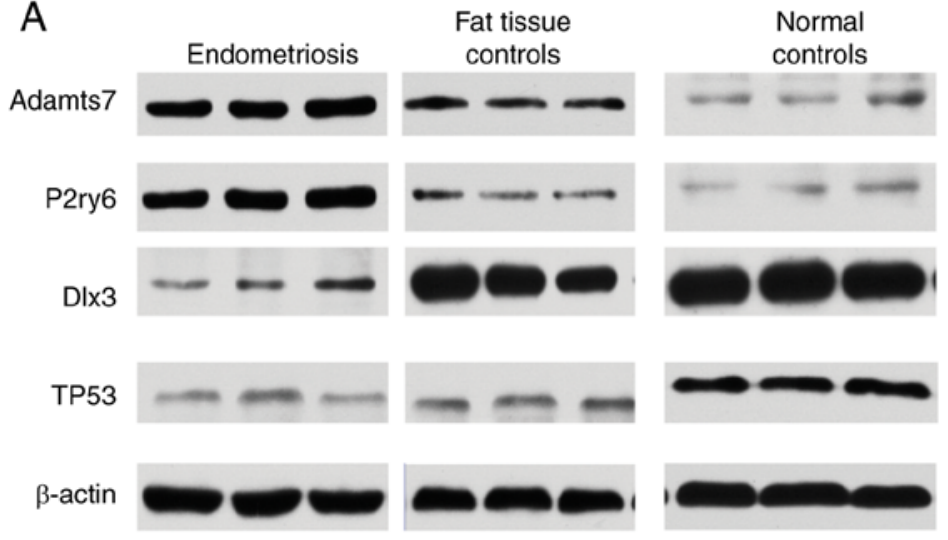

C

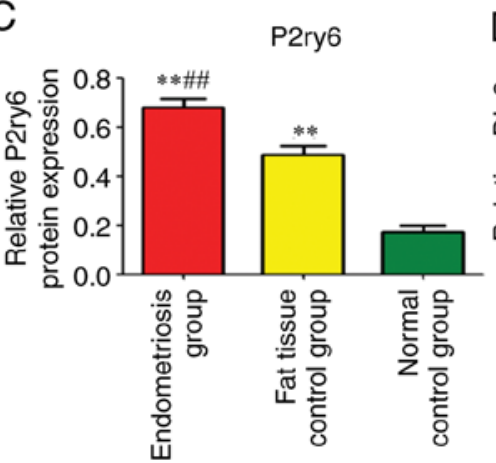

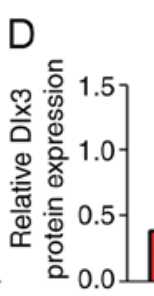

$D 1 \times 3$

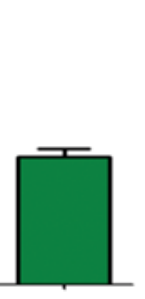

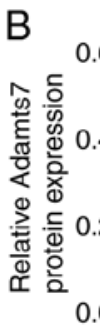

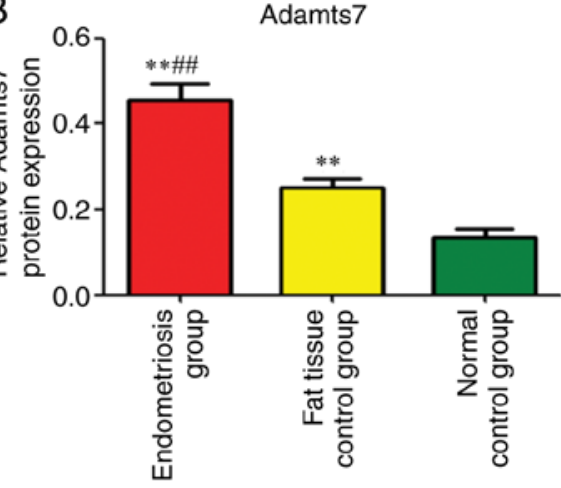

E

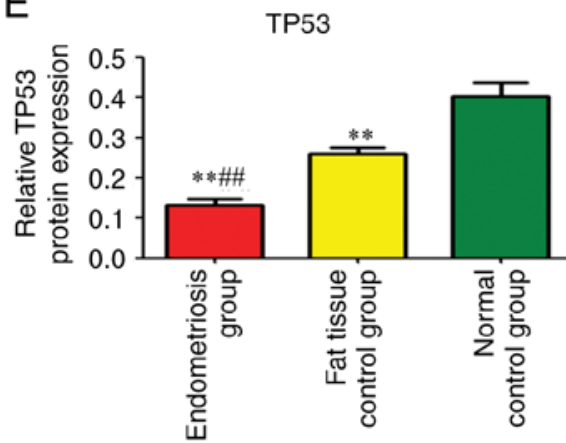

Figure 7. Western blot analysis of uterine tissue in rats. (A) Expression of Adamts7, P2ry6, Dlx3 and Tp53 in the endometriosis group (n=13), adipose tissue control group $(n=8)$ and blank control group $(n=14)$. Quantification of the western blotting results for (B) Adamts7, (C) P2ry6, (D) D1x3 and (E) Tp53. The samples were tested in triplicates. $\beta$-actin was used to normalize the data. ${ }^{* *} \mathrm{P}<0.01$ vs. normal control, ${ }^{\# \#} \mathrm{P}<0.01$ vs. adipose tissue controls. Adamts7, ADAM metallopeptidase with thrombospondin type 1 motif 7; Tp53, tumor protein p53; D1x3, distal-less homeobox 3; P2ry6, pyrimidinergic receptor P2Y6.

female rats, the $\mathrm{X}$ chromosome was selectively silenced and inactivated; during this process, IncRNAXist was activated by the downregulation of ubiquitin ligase Rnf12/RLIM3-5 in the embryonic cells. It has been shown that lncRNAs play a key role in human embryo implantation (25). In the present study, a rat endometriosis model was established by mating to obtain uterine tissues during the implantation window. This study is the first study to the best of our knowledge on the expression 
Table VIII. Comparison between rat and human lncRNA sequences.

\begin{tabular}{llcc}
\hline Rat lncRNA & \multicolumn{1}{c}{ Human lncRNA } & \% identical & lncRNA ID \\
\hline gil672027621|reflXR_592747.1I & p17451 & 90.31 & TCONS_00001579 \\
NONRATT022454 & p44032_v4 & 83.45 & uc001cvx.3 \\
gil672045999|ref|XR_591544.1I & p10107 & 83.29 & ENST00000563759.1 \\
NONRATT014258 & RNA40309|RefSeq_2352_1430 & 90.06 & \\
NONRATT011779 & RNA38792|RefSeq_733_3290 & 81.9 & 100 \\
NONRATT029450 & RNA42607IUCSC_176_6901 & 86.47 & LIT3372 \\
NONRATT028550 & p28817 & 84.17 & ENST00000514073.1 \\
NONRATT003997 & p37546_v4 & 81.42 & LIT3372 \\
NONRATT027560 & p28817 & 88 & 81.71 \\
NONRATT000719 & RNA45098IUCSC_3204_2521 & \\
NONRATT017840 & RNA43455IUCSC_1198_3829 & \\
\hline
\end{tabular}

lnc, long noncoding.

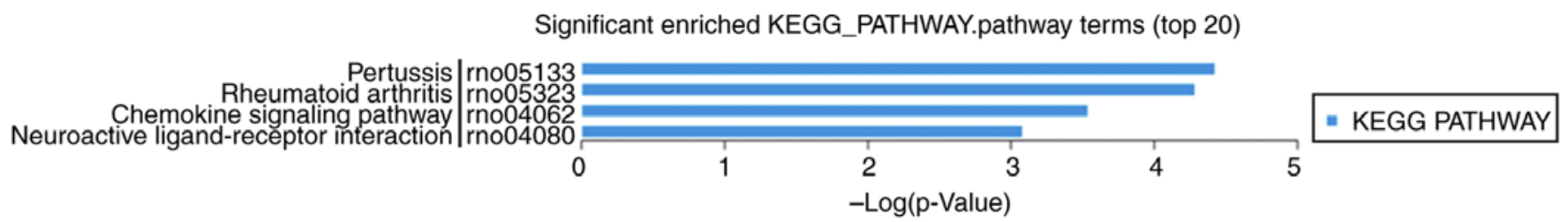

Figure 8. KEGG analysis of differentially expressed lncRNAs. lnc, long noncoding; KEGG, Kyoto Encyclopedia of Genes and Genomes.
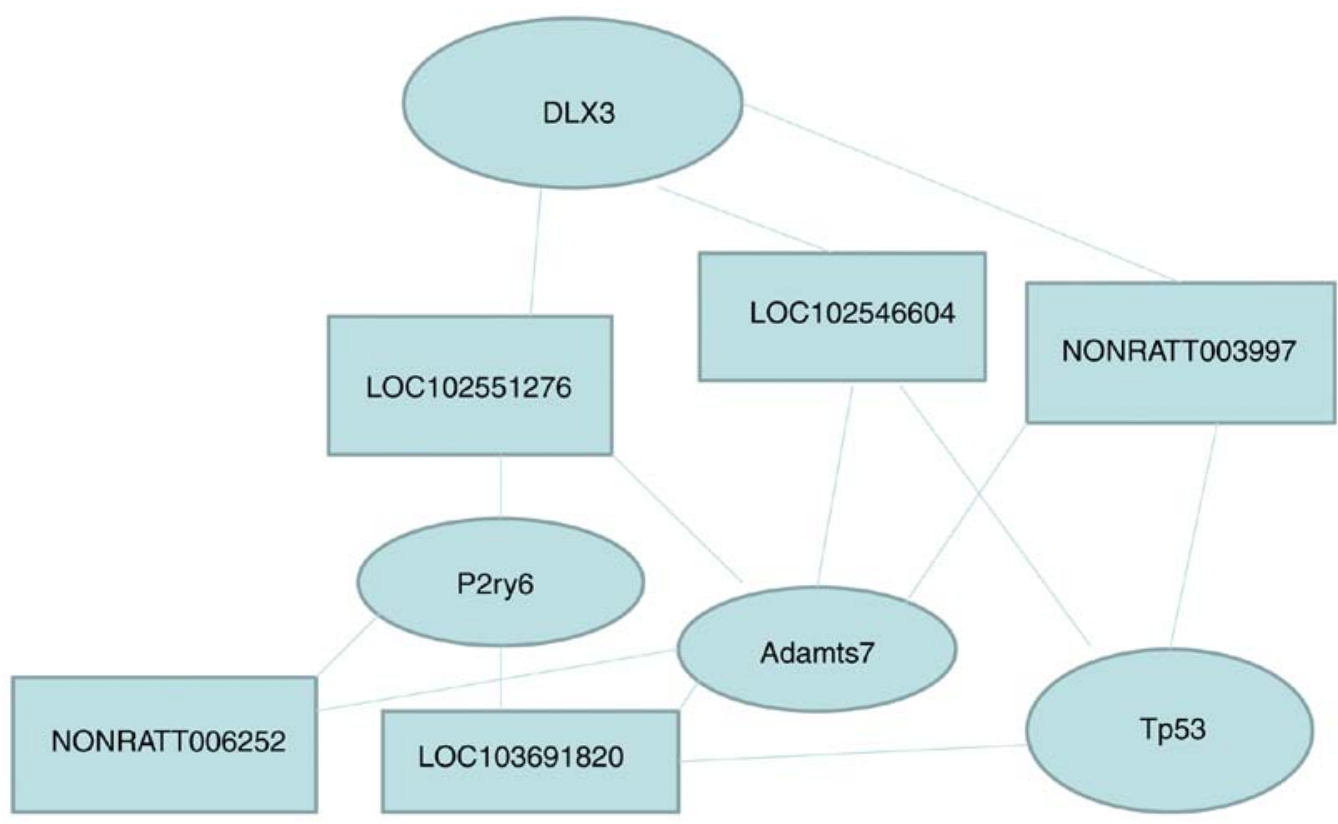

Figure 9. Relationships among the five differentially expressed lncRNAs and the four mRNAs. The lncRNAs and mRNA shown here are those that were validated by quantitative PCR. The samples were tested in triplicates. lnc, long noncoding; Adamts7, ADAM metallopeptidase with thrombospondin type 1 motif 7; Tp53, tumor protein p53; Dlx3, distal-less homeobox 3; P2ry6, pyrimidinergic receptor P2Y6.

profile of IncRNA and mRNA in endometriosis during the implantation window.

Adamts7 belongs to a group of proteins that have platelet-associated activity (26). The overexpression of ADAMTS-7 promotes the decomposition of cartilage oligomeric matrix protein and accelerates the development of osteoarthritis induced by surgery and collagen-induced arthritis (27). In the present study, Adamts7 was mainly expressed in the endometrial stroma, glands and uterine cavity epithelium, the expression in the uterine tissues of rats with 
endometriosis was upregulated, and the expression in the adipose tissue control group was also upregulated in comparison with that of the blank control group. Therefore, it could be hypothesized that implantation failure in endometriosis during the implantation stage could be related to inflammation and the function of secretory glands.

Giannattasio et al (28) showed that as a G-protein combined receptor and a uridine diphosphate receptor, P2ry6 has a high affinity for G-protein combined receptor and uridine-2-phosphate receptor, which is an important endogenous inhibitor of the function of T cells in allergic pulmonary inflammation. Hamby et al (29) showed that transforming growth factor- $\beta 1$, lipopolysaccharide, interferon- $\gamma$ and other inflammatory factors can cause immune injury in astrocytes through the expression of P2ry6, leading to nervous system dysfunction. In the present study, the expression of P2ry6 in the uterine tissues of rats with endometriosis was upregulated during the implantation stage and the expression in the operation control group was upregulated in comparison with that of the blank control group. Therefore, this study considered that the gene regulation of P2ry6 in rats with endometriosis during the implantation window might be related to inflammation and hormone levels, which needs to be confirmed.

Dlx 3 has been widely studied in the course of pregnancy and plays an important role in the formation of the placenta (30-32). DLX3 is expressed in the placenta tissues during human early pregnancy and plays an important regulatory role in the trophoblastic layer, syncytial layer and the formation of primary villi (33). Berghorn et al (34) showed that DLX3 in the placental tissues of 8.5-day mouse embryonic development was not detected, but DLX3 could be detected at 9.5 days and continued to 15.5 days. DLX3 produces $3 \beta$-hydroxysteroid dehydrogenase (VI) during the process of the secretion of progesterone by placental trophoblast cells and the expression of DLX3 is not detected in the embryonic stem cells (Rcho-1) of rats (34). In the present study, the expression of DLX 3 in the endometrial stroma in rats with endometriosis during the implantation window was not significantly different from that of the operation control group and they were both decreased compared with in the blank control group. It was hypothesized that the effect of DLX3 on rats with endometriosis during the implantation window was mainly reflected in the endometrial stroma, which might not be related to gland activity and hormone levels, but more closely related to inflammation. Nevertheless, changes in the expression of DLX3 could be due to the surgery (35). Additional studies are necessary to examine this.

Tp53 acts as a bridge in the exchange process of pregnant mother and fetus in the early stages. The inactivation of Tp53 is affected by the preimplantation factor and may cause the apoptosis of placental cells, indicating that the interaction of Tp53 and implantation factors in human placental cytotrophoblasts promotes the survival and growth of embryonic cells (36). The expression profile of TP53 fluctuates during pregnancy (37). In human placental cells, adiponectin induces caspase activity by increasing the expression of TP53 and BAX, leading to a decrease in the expression of adiponectin receptors, and affecting the nutrient transport function of the placenta (38). Tp53 was also a downregulated gene in the uterine tissues of rats with endometriosis during the implantation window, but there was no significant difference between the endometriosis group and operation control group, both of them showing downregulated levels in comparison with those of the blank control group. Tp53 probably plays an important role in the formation of endometrial receptivity in rats with endometriosis during the implantation window, which might be related to the endometriosis-associated inflammatory characteristics and gland secretion. As for DLX3, changes in Tp53 could also be due to surgery (39). This will have to be examined in the future.

The present study is not without limitations. Although the present study could efficiently avoid the effects of the menstrual cycle in different individuals, it was still impossible to avoid the disadvantages of using animal experiments. There were also some differences among animals and the endometrium could not be separated because the uterine tissues of rats are too small. Therefore, the gene expression profile in the uterine tissues was decreased compared with the endometrium. Moreover, although human IncRNA sequence are highly similar to rats', there are still some differences (Table VIII). Therefore, the next step will be to compare the degree of conservation of human and rat lncRNA sequences. On the basis of the obtained gene data of lncRNA and mRNA expression profiles in the uterine tissues of rats with endometriosis during the implantation window, five lncRNAs were compared with the conservative sequence of the human IncRNA database, showing that the IncRNAs were highly consistent. The correlation analyses indicate a relationship among the IncRNAs and mRNAs, but not the exact causal nature of the relationships. Finally, no functional and mechanistic experiments were performed to confirm the GO and KEGG results. Additional studies are still necessary to confirm the roles of the differentially expressed lncRNAs and mRNAs identified in the present study.

The results showed that the changes in the expression of IncRNAs, mRNAs and proteins (Adamts7, P2ry6, Dlx3 and TP53) may possibly affect the endometrial receptivity in rats with endometriosis during the implantation window, probably resulting in implantation failure of the embryo. This study provides new insights to investigate the pathogenesis of the disease and new clues about the possible causes of implantation failure in patients with endometriosis. It could ultimately reveal treatment targets for endometriosis infertility, but RNA stability is still a major barrier to the successful development of RNA therapeutics.

\section{Acknowledgements}

Not applicable.

\section{Funding}

No funding was received.

\section{Availability of data and materials}

All data generated or analyzed during this study are included in this published article.

\section{Authors' contributions}

HC conceived and coordinated the study, designed, performed and analyzed the experiments, wrote the paper. XZ, ZL, YZ, 
JL carried out the data collection, data analysis, and revised the paper. All authors reviewed the results and approved the final version of the manuscript.

\section{Ethics approval and consent to participate}

This study was approved by the experimental animal center of Peking Union Medical College Hospital and Chinese Academy of Medical Sciences (permit no. XHDW-2016-000). All experiments were performed in accordance with the principles of experimental animal management and protection. The rats were humanely sacrificed as necessary to prevent suffering.

\section{Patient consent for publication}

Not applicable.

\section{Competing interests}

All authors declare that they have no competing interests.

\section{References}

1. Bedaiwy MA, Alfaraj S, Yong P and Casper R: New developments in the medical treatment of endometriosis. Fertil Steril 107: 555-565, 2017.

2. Zhao Y, Gong P, Chen Y, Nwachukwu JC, Srinivasan S, Ko C, Bagchi MK, Taylor RN, Korach KS, Nettles KW, et al: Dual suppression of estrogenic and inflammatory activities for targeting of endometriosis. Sci Transl Med 7: 271ra9, 2015.

3. de Ziegler D, Pirtea P, Galliano D, Cicinelli E and Meldrum D: Optimal uterine anatomy and physiology necessary for normal implantation and placentation. Fertil Steril 105: 844-854, 2016.

4. Lessey BA and Kim JJ: Endometrial receptivity in the eutopic endometrium of women with endometriosis: It is affected, and let me show you why. Fertil Steril 108: 19-27, 2017.

5. Ghazal S, McKinnon B, Zhou J, Mueller M, Men Y, Yang L, Mueller M, Flannery C, Huang Y and Taylor HS: H19 lncRNA alters stromal cell growth via IGF signaling in the endometrium of women with endometriosis. EMBO Mol Med 7: 996-1003, 2015.

6. Liang Z, Chen Y, Zhao Y, Xu C, Zhang A, Zhang Q, Wang D, He J, Hua W and Duan P: miR-200c suppresses endometriosis by targeting MALAT1 in vitro and in vivo. Stem Cell Res Ther 8: $251,2017$.

7. Wang M, Hao C, Huang X, Bao H, Qu Q, Liu Z, Dai H, He S and Yan W: Aberrant expression of lncRNA (HOXA11-AS1) and homeobox A (HOXA9, HOXA10, HOXA11, and HOXA13) genes in infertile women with endometriosis. Reprod Sci 25: 654-661, 2018.

8. Sha L, Huang L, Luo X, Bao J, Gao L, Pan Q, Guo M, Zheng F and Wang H: Long non-coding RNA LINC00261 inhibits cell growth and migration in endometriosis. J Obstet Gynaecol Res 43: 1563-1569, 2017.

9. Sun PR, Jia SZ, Lin H, Leng JH and Lang JH: Genome-wide profiling of long noncoding ribonucleic acid expression patterns in ovarian endometriosis by microarray. Fertil Steril 101: 1038-1046 e7, 2014

10. Rekker K, Saare M, Eriste E, Tasa T, Kukuškina V, Roost AM, Anderson K, Samuel K, Karro H, Salumets A and Peters M: High-throughput mRNA sequencing of stromal cells from endometriomas and endometrium. Reproduction 154: 93-100, 2017.

11. Wang Y, Li Y, Yang Z, Liu K and Wang D: Genome-wide microarray analysis of long non-coding RNAs in eutopic secretory endometrium with endometriosis. Cell Physiol Biochem 37: $2231-2245,2015$

12. Vernon MW and Wilson EA: Studies on the surgical induction of endometriosis in the rat. Fertil Steril 44: 684-694, 1985.

13. Keenan JA, Williams-Boyce PK, Massey PJ, Chen TT, Caudle MR and Bukovsky A: Regression of endometrial explants in a rat model of endometriosis treated with the immune modulators loxoribine and levamisole. Fertil Steril 72: 135-141, 1999.
14. Cai H,Zhu XX, Li ZF, Zhu YP and Lang JH: MicroRNA dysregulation and steroid hormone receptor expression in uterine tissues of rats with endometriosis during the implantation window. Chin Med J (Engl) 131: 2193-2204, 2018.

15. Makrigiannakis A, Zoumakis E, Kalantaridou S, Coutifaris C, Margioris AN, Coukos G, Rice KC, Gravanis A and Chrousos GP: Corticotropin-releasing hormone promotes blastocyst implantation and early maternal tolerance. Nat Immunol 2: 1018-1024, 2001.

16. Xiao L, Wu J, Wang JY, Chung HK, Kalakonda S, Rao JN, Gorospe M and Wang JY: Long noncoding RNA uc. 173 promotes renewal of the intestinal mucosa by inducing degradation of microRNA 195. Gastroenterology 154: 599-611, 2018.

17. Livak KJ and Schmittgen TD: Analysis of relative gene expression data using real-time quantitative PCR and the 2(-Delta Delta C(T)) method. Methods 25: 402-408, 2001.

18. Konno R, Yamakawa H, Utsunomiya H, Ito K, Sato S and Yajima A: Expression of survivin and Bcl-2 in the normal humanendometrium. Mol Hum Reprod 6: 529-534, 2000.

19. Guttman M, Amit I, Garber M, French C, Lin MF, Feldser D, Huarte M, Zuk O, Carey BW, Cassady JP, et al: Chromatin signature reveals over a thousand highly conserved large non-coding RNAs in mammals. Nature 458: 223-227, 2009.

20. Wong ES, Schmitt BM, Kazachenka A, Thybert D, Redmond A, Connor F, Rayner TF, Feig C, Ferguson-Smith AC, Marioni JC, et al: Interplay of cis and trans mechanisms driving transcription factor binding and gene expression evolution. Nat Commun 8: 1092, 2017.

21. Wang Q, Wang N, Cai R, Zhao F, Xiong Y, Li X, Wang A, Lin P and Jin Y: Genome-wide analysis and functional prediction of long non-coding RNAs in mouse uterus during the implantation window. Oncotarget 8: 84360-84372, 2017.

22. Powell JE, Fung JN, Shakhbazov K, Sapkota Y, Cloonan N, Hemani G, Hillman KM, Kaufmann S, Luong HT, Bowdler L, et al: Endometriosis risk alleles at $1 \mathrm{p} 36.12$ act through inverse regulation of CDC42 and LINC00339. Hum Mol Genet 25: 5046-5058, 2016

23. Sigurgeirsson B, Amark H, Jemt A, Ujvari D, Westgren M, Lundeberg $\mathrm{J}$ and Gidlöf S: Comprehensive RNA sequencing of healthy human endometrium at two time points of the menstrual cycle. Biol Reprod 96: 24-33, 2017.

24. Shin J, Wallingford MC, Gallant J, Marcho C, Jiao B, Byron M, Bossenz M, Lawrence JB, Jones SN, Mager J and Bach I: RLIM is dispensable for $\mathrm{X}$-chromosome inactivation in the mouse embryonic epiblast. Nature 511: 86-89, 2014.

25. Bouckenheimer J, Assou S, Riquier S, Hou C, Philippe N, Sansac C, Lavabre-Bertrand T, Commes T, Lemaitre JM, Boureux A and De Vos J: Long non-coding RNAs in human early embryonic development and their potential in ART. Hum Reprod Update 23: 19-40, 2016.

26. Liu CJ: The role of ADAMTS-7 and ADAMTS-12 in the pathogenesis of arthritis. Nat Clin Pract Rheumatol 5: 38-45, 2009.

27. Zhang Y, Wei F and Liu CJ: Overexpression of ADAMTS-7 leads to accelerated initiation and progression of collagen-induced arthritis in mice. Mol Cell Biochem 404: 171-179, 2015.

28. Giannattasio G, Ohta S, Boyce JR, Xing W, Balestrieri B and Boyce JA: The purinergic G protein-coupled receptor 6 inhibits effector $\mathrm{T}$ cell activation in allergic pulmonary inflammation. J Immunol 187: 1486-1495, 2011.

29. Hamby ME, Coppola G, Ao Y, Geschwind DH, Khakh BS and Sofroniew MV: Inflammatory mediators alter the astrocyte transcriptome and calcium signaling elicited by multiple G-protein-coupled receptors. J Neurosci 32: 14489-14510, 2012.

30. King JH, Kwan STC, Yan J, Klatt KC, Jiang X, Roberson MS and Caudill MA: Maternal choline supplementation alters fetal growth patterns in a mouse model of placental insufficiency. Nutrients 9: E765, 2017.

31. Murthi P, Hiden U, Rajaraman G, Liu H, Borg AJ, Coombes F, Desoye G, Brennecke SP and Kalionis B: Novel homeobox genes are differentially expressed in placental microvascular endothelial cells compared with macrovascular cells. Placenta 29: 624-630, 2008.

32. Clark PA, Brown JL, Li S, Woods AK, Han L, Sones JL, Preston RL, Southard TL, Davisson RL and Roberson MS: Distal-less 3 haploinsufficiency results in elevated placental oxidative stress and altered fetal growth kinetics in the mouse. Placenta 33: 830-838, 2012.

33. Chui A, Pathirage NA, Johnson B, Cocquebert M, Fournier T, Evain-Brion D, Roald B, Manuelpillai U, Brennecke SP, Kalionis B and Murthi P: Homeobox gene distal-less 3 is expressed in proliferating and differentiating cells of the human placenta. Placenta 31: 691-697, 2010. 
34. Berghorn KA, Clark PA, Encarnacion B, Deregis CJ, Folger JK Morasso MI, Soares MJ, Wolfe MW and Roberson MS: Developmental expression of the homeobox protein distal-less 3 and its relationship to progesterone production in mouse placenta. J Endocrinol 186: 315-323, 2005.

35. Zhan Y, Li X, Gou X, Yuan G, Fan M and Yang G: DLX3 inhibits the proliferation of human dental pulp cells through inactivation of canonical Wnt/ $\beta$-catenin signaling pathway. Front Physiol 9: 1637,2018

36. Moindjie H, Santos ED, Gouesse RJ, Swierkowski-Blanchard N, Serazin V, Barnea ER, Vialard F and Dieudonné MN: Preimplantation factor is an anti-apoptotic effector in human trophoblasts involving p53 signaling pathway. Cell Death Dis 7: e2504, 2016.

37. Kaczmarek MM, Krawczynski K, Najmula J, Reliszko ZP, Sikora M and Gajewski Z: Differential expression of genes linked to the leukemia inhibitor factor signaling pathway during the estrus cycle and early pregnancy in the porcine endometrium. Reprod Biol 14: 293-297, 2014.
38. Duval F, Santos ED, Poidatz D, Serazin V, Gronier H, Vialard F and Dieudonné MN: Adiponectin inhibits nutrient transporters and promotes apoptosis in human villous cytotrophoblasts: Involvement in the control of fetal growth. Biol Reprod 94: 111, 2016.

39. Hausmann R, Nerlich A and Betz P: The time-related expression of p53 protein in human skin wounds-a quantitative immunohistochemical analysis. Int J Legal Med 111: 169-172, 1998.

This work is licensed under a Creative Commons Attribution-NonCommercial-NoDerivatives 4.0 International (CC BY-NC-ND 4.0) License. 